\title{
Inter- multi- and trans-disciplinary approaches in astronomy education research
}

\author{
Nicoletta Lanciano"*t \\ Universitá di Roma «La Sapienza» and Gruppo di ricerca sulla pedagogia del cielo del \\ Movimento di Cooperazione Educativa, Rome, Italy
}

\begin{abstract}
Looking at human and natural reality, based on experience and awareness of its complexity, the western style of knowledge was divided into disciplines. These developed their own language and methods in relation to their objects of study. The separation, useful in some stages of study and in their specific development, was often simplistic and damaging both in scientific elaboration, to meet the challenges that nature and the future offers us, and in didactic transposition of knowledge. Studies in general education and cognitive psychology, and more recently neurosciences, show that aspects of different disciplines are formed and stimulated in parallel, and also motion and cognition are linked in the brain. The research confirms that cognitive experience is linked to the body and to emotions, more than school organizations often wanted to recognize. Therefore, inter-, multi- and trans-disciplinary approaches better relate to the objects of study, to teaching methodologies, and to teaching research methods. To analyze these issues, I present reflections from my Astronomy teaching experiences with students of different ages in Italy and elsewhere, and I present open questions about teaching and learning, in and out of school, and about teacher training.
\end{abstract}

\section{Introduction}

Looking to the human and natural reality, coming from the experience and from awareness of its complexity, the western-style knowledge conceived separate disciplines. These developed their own languages and methods in relation to their study objects. What are disciplines? After the natural philosophers in 1600, the disciplines were well defined and by 1800 their rigid compartmentation took place, becoming "classic disciplines." The word "discipline" descends from the Latin discipulus that means learner and is connected with learning. A discipline is not a concept, and is much more than its own content. A discipline refers to subjects, content of study and teaching, that is, the field of knowledge which is taught, and an extended system of rules, organization and methods. Ervin Laszlo, a contemporary philosopher of science systems, says "my job is not to be a specialist", and

Corresponding author nicoletta.lanciano@uniroma1.it 
writes: "The disciplines in science are artefacts.... They are often necessary ... There are no boundaries in nature that uniquely match the boundaries of the disciplines." Therefore, inter, multi and trans-disciplinary approaches are related to the objects of study, to teaching methodologies and to the teaching research methods, using points of view of the different disciplines for the same assets and the same themes. For example, general theories of teaching, pedagogy and the teaching methods of the scientific disciplines together help to develop, in a natural way, capacity in a topic, in contrast to analysis of language consistency. I wonder what contributions and roles that different arts and techniques, the activation of the entire body (kinesthetics), craftsmanship, and attention to emotions may have if we want to teach in a responsible, durable and ethical way.

I show in this paper examples of Astronomy, specifically about the geographical conditions of countries at different latitudes and their impact on perceptual, cognitive and educational aspects. Cultural differences that affect individual, national or local communities are the area of ethnoastronomy research that I do not address in this paper.

Inter-, multi- and trans-disciplinary approaches in Astronomy education research therefore regard contents and methods. We can define:

- Interdisciplinarity concerns and interests disciplines that have a common theme or object such as the study of the sky. Astronomy and meteorology, but also poetry, mythology and philosophy are integrated in studying the sky, each discipline uses its own methods.

- Multidisciplinarity is an epistemological approach, where there is the same goal of studying an object, but each discipline approaches the object of study independently, using its own methods. Knowledge is parceled out and not integrated.

- Transdisciplinarity is a new "aptitude", that goes beyond the types of issues of the classical disciplines. J. Piaget in 1970 defined "... Finally, we hope to see in the future the development of interdisciplinary relationships at a higher level that could be referred to as "transdisciplinary ", which should not be limited to recognizing interactions or reciprocity through specialized research, but which will have to identify those connections within a total system without any stable boundaries the disciplines themselves." Basarab Nicolescu (a physicist) in 1985 introduced the concept of "beyond the disciplines". It seems a paradox that from the heart of an exact science, physics, he comes to the idea of a limit to disciplinary knowledge. Blanchard-Laville recently proposed that co-disciplinary analysis is co-constructing of meaning of a study object. For example, when I ask university students "What is latitude on Earth?", I suggest to them that to understand this invisible angle in the centre of the sphere, to use a 3D model. We can look at the constructed models with the eyes of the disciplinary teaching skills, to see if it is the correct angle, but also with relational skills, looking at how the students work in the groups. Or we can observe the construction of the model and the students' attention to the technical skills: in this case the teacher observes if it is possible to use the model at different latitude (is it a dynamic model) and if it is so robustly made that it is possible to use it without breaking. This means that several specialists can look at a didactic situation with different questions in mind:

- Which models and useful knowledge do learners use?

- Which mistakes do they make?

- Which specific and epistemological difficulties have they found about angles?

- Do they use a coherent language for the argument?

- Who has brilliant ideas? 
- Do students accept different, new or divergent ideas?

General education and cognitive psychology, and most recently the neurosciences, recognize how body movement and cognitive relationships are related in our brain's synapses (Dehaene, 2010). The Chilean psychoanalyst, I. Matte Blanco (1975) wrote that cognitive experience is related to the body and the emotions, and that there is no thinking without emotion. We need to accept and recognize that we use bi-logic, in the sense elaborated by Matte Blanco, and not only Aristotelian logic yes/no, right/wrong, 0/1 that imposes a choice. Our rational logic is linked to the logic of the unconscious, so we live with a bi-logic that mixes the two types of logic. In the symmetrical logic of the unconscious we can experiment with emotions or dreaming, where the principle of reversability is valid. Thus, the positive emotion of amazement and discovery in directly observing the sky helps attention and memory.

I perceive great problems with reductionism and simplification in teaching science at all levels of school, from children to adults. Instead of teaching to recognize the levels of complexity and of approximation in a question or a subject, very often books, websites and teachers show simple and linear presentations. They use answers and affirmative phrases, instead of teaching by questioning. For example, I analyze the tale about Eratosthenes's measurement of the Earth meridian. For this measurement, in a non-reductionist way, I show that many questions are possible in different domains and at different levels of historical reconstruction:

- What sources do we have for Eratosthenes's work? (History)

- Where was the tropic of Cancer at that time (3rd century B.C.)? (Astronomy)

- Were Alexandria and Syene on the same meridian? How could he know it? (Geography, Astronomy)

- Which method did they used to measure the distance? (Technology)

- Which kind of sundial did Eratosthenes use? (Astronomy)

- How much did a stadium measure in km? (History)

- $360^{\circ}: 7^{\circ} 12^{\prime}=5000$ stadia: $\mathrm{x}$. (Mathematics)

- Did he use a vertical rod (gnomon, casting a shadow on the ground) or a skaphe (a hemispherical bowl with a vertical gnomon) (Astronomy) (Lanciano, Berardo, 2016)?

- What impresses us about a man who more than 2000 years ago, understood how large the Earth is. (Emotion)

We know that we need big models and large spaces to help develop visual-spatial reasoning but, on the contrary, many teachers only use the classrooms in schools and universities. With a group of teachers-in-training in a large, outdoor space at local solar noon, we first find the meridian by looking at the shadows cast by our bodies, and mark it with a rope: this is the South-North line. (Figure 1)

Contributions to education and to school also come from other domains. Pedagogy needs other ways of looking and different approaches to be effective in society. One of these is medicine, whose investigative methods are to observe, record, interpret and predict symptoms - it gives very important guidance. Some European physicians in the 20th century became well-known pedagogical personalities. These are: Maria Montessori in Italy, Ovide 


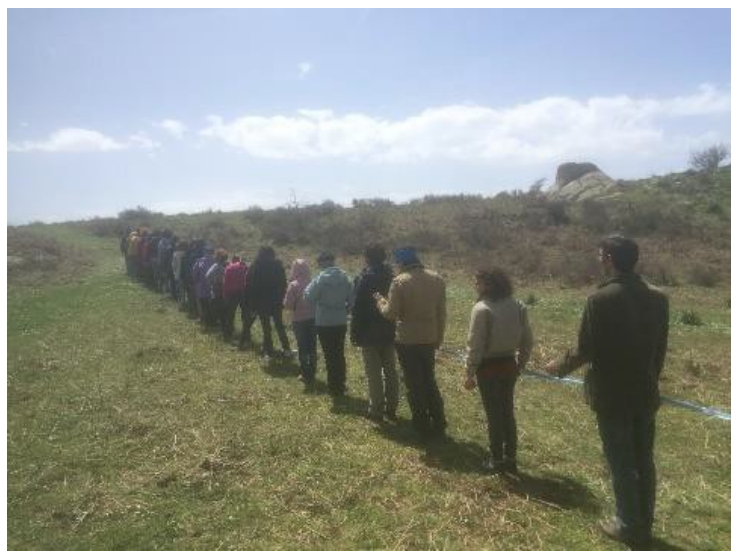

Figure 1.

Decroly in Belgium, Janus Korjak in Poland and Emmi Pikler in Hungary. In the area of catholic thought in Italy there is a special person, don Lorenzo Milani (1923-1967) and his school in Barbiana. He denounced the class-based selection that disadvantaged the children of workers and peasants in Italian schools. In the «Lettera a una professoressa», a letter written by Milani 's students' group, the usual school is defined "as a hospital that cares for the healthy and rejects the sick". In the Barbiana school there was no separation between manual and intellectual work: building tables and writing, calculating or building a precise astrolabe, etc. all had the same value and very close relationship.

\section{Not only Astronomy}

Astronomy education research is in dialog with other disciplines in education research and teacher training, like research in astronomy, maths, physics, and education in mathematics, physics, geology, pedagogy, neurosciences, history of science and epistemology. But in my work very important assistance comes from other areas of human activity like theatre and training of actors, different arts and crafts, and the environment of museums and monuments. For example, actors have very acute visuo-spatial skills, and they produce dramatic works using space and perspective, and illumination of objects and spaces.

\subsection{Didactic of mathematics}

In mathematics, and especially geometry, we define the micro space, meso space, macro space and mega space in relation to the dimensions of the space that we consider. These spaces are different from each other depending on the each person's particular definition (Lanciano, 1996). The vertical direction, for example, is the direction of gravity, like the plumb on the wire (Figure 2) . In meso space, i.e. a garden or a room, the vertical direction is perpendicular to the horizontal plane. In the mega space of planet Earth, the direction of gravity is the radial direction. (Figure 3) 


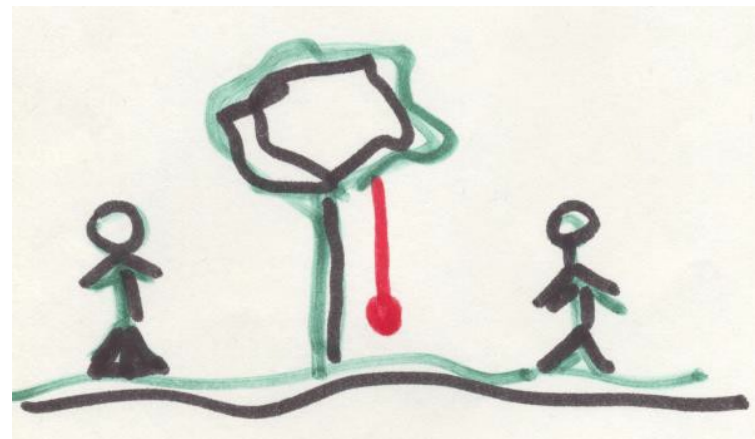

Figure 2

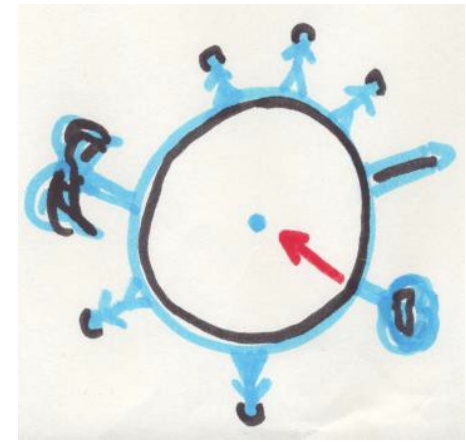

Figure 3

\subsection{Epistemology}

Epistemologically in astronomy we have to consider the Copernican Revolution. The epistemological problem is that we talk "like Ptolemy and we think like Copernicus" because:

- we see the Sun moving on the horizon from the orient to its culmination at noon, and moving to the occidental part of the horizon, every day;

- we say: "the Sun rises" or "the Sun sets", and not "the Earth rotates so that the Sun ....".

- We speak as if we were on a central, static Earth; but we know and we think about a heliocentric point of view and we think of the Earth as a dynamic celestial body.

We accept this coexistence in our perception, in our language and in our thinking

- of a topocentric vision of Sun

- and a heliocentric point of view.

This is an example of complexity, and for the Sun-Earth system we -children and adults, like the astronomers- hold two different ideas at the same time. Everybody is, in our point of view, "Ptolemaic" and "Copernican" at the same time. Which idea, language, schema or vocabulary to use depends on the situation:

- if we point a telescope,

- if we are on a boat in the sea,

- if we study the orbits of the planets.

A model, like every point of view, may be more useful in a different situation.

In our didactical experience with Astronomy, with people of difference ages, we find that it is necessary to become a good "Ptolemaic observer", with a solid geocentric and geostatic experience, before one becomes a convinced "Copernican" one. We refuse to say that in school we want to move students from a Ptolemaic view to a Copernican view. We want to improve the observation of phenomena in real time, the rise and the set of the Sun, of the Moon, of the stars... and the description of these observations before asking "who moves?". It is not very interesting, in my opinion, to know the scientific answer "The Earth rotates around the Sun" if a student never observes a reciprocal movement! 


\subsection{Pedagogy}

In pedagogy we find Ioannes Comenius, a European educator of the 17th century, an authoritative and valuable source. Thus, the principle for which any teaching must begin is from the activity of the senses, in contrast to the teaching practice of his time that was based on words! Comenius, in his book Didactica Magna, denounces and criticizes as ineffective a method which begins with abstract rules and only later, utilizes examples to clarify the rules.

In 1996, Mario Lodi, an Italian teacher of the Freinet school of pedagogy wrote: "Never as today the child needs to use the senses and mind to relate to the real world in which ways, to return to making concrete experiences." (Figure4)

We have to pay attention! Learning to look, to pose questions, is a spontaneous action only in early childhood; with high school students, the teachers need to invite them to rediscover the way to observe and to be in a relationship with the environment and ask questions.

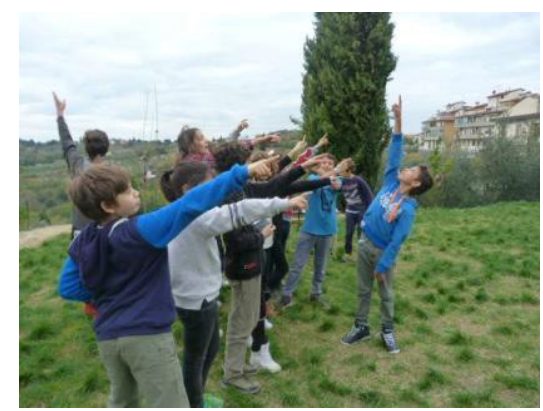

Figure 2

\section{Rethinking astronomy for teaching}

Many people are astonished and are ready to smile or to be scandalized about "bad" results from national and international assessments of student learning (IEA, PISA). Journal articles about scientific illiteracy shows that adults and students lack elementary knowledge in the field of astronomy: but many countries invest very little money in school and teacher training. And in the university, research on teaching is penalized in terms of the value given to specialist publications and positions: as it is thought that to know a disciplinary field automatically means to be able to teach it appropriately.

A response in Europe came in 2007 when the European Commission published a report titled Scientific Education NOW: A Renewed Pedagogy for the Future of Europe, written by the High Level Group on Science Education. In its introduction they write: "Since the origins of the declining interest among young people for science studies are found largely in the way science is taught in primary and secondary schools, this is the main focus" One of the recommendations of the report is to improve science education through new forms of pedagogy, specifically inquiry based science education (IBSE).

With Yves Chevallard (specialist in maths didactics) we define "didactic transposition" as that process of transformation that we must do to bring concepts developed by the scientific community, into the school curricula and to actually teach the concept at the appropriate level. Encyclopedic knowledge is organized in a different way 
from teaching knowledge. And a further transformation of concept order is useful when we want to teach the concepts with the goal of developing encyclopedic knowledge.

\subsection{Steps of educational research}

I discuss some steps of educational research in Astronomy, bearing in mind some very special features of the discipline: astronomers are passive observers because they cannot plan an experiment like a physicist or a chemist does. To see an eclipse, it is necessary to wait for it to happen. Furthermore, the large spaces and long times of evolution in astronomy have a very different scale compared to our quotidian life. Below I describe some steps. (Lanciano, 1996)

\subsubsection{Collection of initial conceptions}

Learners often have already some previous ideas about subjects that someone teaches them: some ideas are more structured even if not completely correct or similar to that accepted in the scientific community. It can be dangerous to ignore that learners have previous ideas. A collection of initial conceptions is made by observing and listening to learners; their initial conceptions are often solid and resistant, articulated real conceptions.

If students say, "In Summer the Earth is closer to the Sun ", they perhaps know that there are seasons when the relationship between Earth and Sun change, they know especially that there is a difference in distance. But they do not consider the difference between what happens in the two hemispheres and they show egocentric and local thinking in that in their Summer the Sun is closer to the Earth. Perhaps they think that the distance is the cause of the season. In fact, it is very difficult to "perceive" a difference between the period when the Sun is closer and when it is farther away.

Another example of an initial conception is synthesized in the sentence "At noon the Sun is at the Zenith". Italian students know that in a day there is a difference in the length of the shadow but they have not observed what happens at noon at an Italian latitude $\left(+37\right.$ to $\left.+47^{\circ}\right)$. They are ready to understand the symmetric situation of the position of the Sun between sunrise and sunset reaching its peak at noon. The problematic aspect of their conception concerns the position of the Sun at noon and the observation of the shadow at noon: in Italy it doesn't disappear, because of the northern latitude of the country. In fact, this sentence shows that this concept is not as deeply held by students as the idea of a spherical planet.

In the literature of science teaching, we found different terms that show very important differences among researchers all over the world, from the 1970s until today in the investigation about mental representations. Like Giordano and Gagliardi observed (Giordano, Gagliardi, 2014) we found negative terms like misconceptions, errors and mistakes, misunderstandings, preconceptions and positive ones like spontaneous or alternative conceptions, initial conceptions, fantastic childhood hypotheses.

\subsubsection{Analysis of difficulties, obstacles and mistakes}

Difficulties, obstacles and mistakes can be perceptive, conceptual-epistemological or psychological-emotional.

In the years 1990-95 some researchers asked young children to draw People where they live on the Earth with clouds and rain. I changed the question a bit and I ask learners, from 8 to 80 years old, to draw EARTH WITH RAIN AND CLOUDS. My question is 
"ambiguous" because in Italian the same word "earth" means planet as well as ground (Figure 5,9). I found some difficulties like the egocentrism of one's position on Earth and no consideration of other positions on it at different latitudes; some obstacles like the flat representation of a 3D space phenomenon, and mistakes like not considering the sense of gravity around the Earth, and the picture of a round Earth in a space with an absolute vertical direction (Figure 6,7,8).

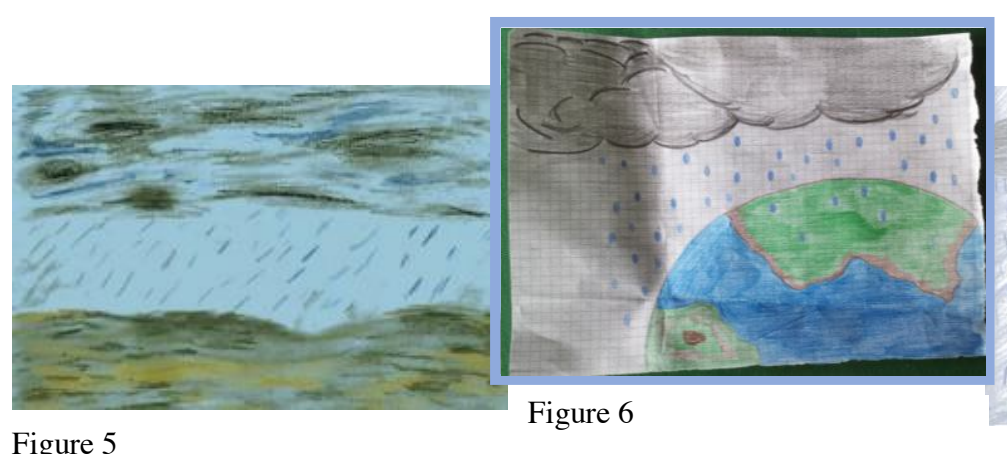

Figure 5

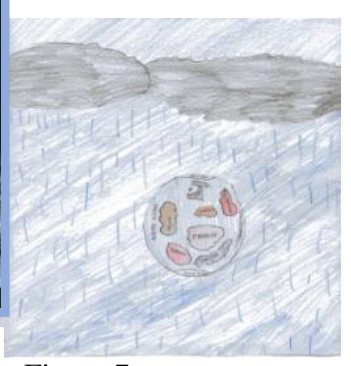

Figure 7

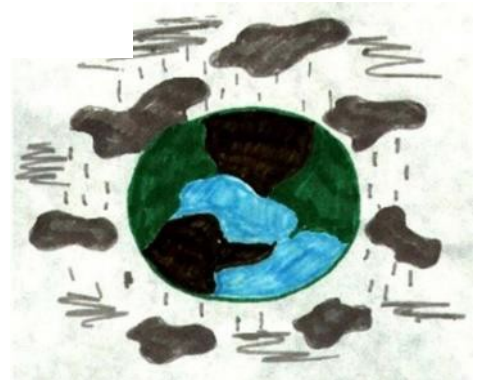

Figure 8

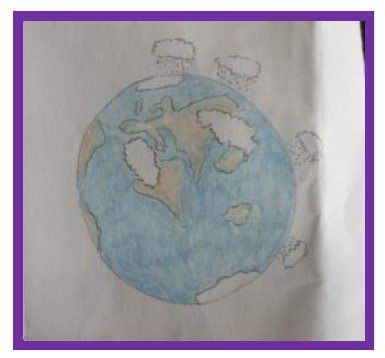

Figure 9

Among the didactical obstacles, first I consider the lack of direct observation of the sky in the day and at night in teaching astronomy. Books, virtual instruments and planetarium programs can't substitute for the direct viewing of the sky's horizon: the path between what you see and what you know is dialectical, and which needs to be made outdoors, with children and with adults!

The language used in school, in particular in science, is verbal and highly symbolic: this is a reason for stumbling of those less dominant learners, or who prefer other ways of communication: the use of expressive forms, such as visual language, the language of poetry, of body movement and of touch, and the arts that are often useful for involving everyone. "When it's just the head that we use I feel blocked. Singing opens up and creates immediate intimacy that makes me feel free to bring people around in the group to help me when I do not understand." wrote Margherita, a teacher in training in a residential Course of the Gruppo di ricerca sulla pedagogia del cielo of the MCE.

\subsubsection{Introduction of useful activities to expand the concept validity}

The purpose of the didactic action is to expand the concepts' range of validity rather than replace a previous concept with a new one or just add new concepts. 
Introducing directly the astronomical horizon does not help to build this concept firmly, especially in relation to the movements of the stars and the directions of their rise and set. To observe the movements of the celestial bodies, we need a system of reference, so we have to pay attention to the local horizon in our local and topocentric vision (Lanciano, 1986). To better observe the $360^{\circ}$ local horizon, I suggest using some gestures with the arm and hand open, to make angular measurements and, then have each draw one portion of the $360^{\circ}$ of the horizon. Using the pictures together the learners "construct" a material reference system where they can mark what they observe, the rise, set and different positions, in time, of the Sun and the Moon.

So, from the local horizon that they can see, learners can expand the concept of horizon to the astronomical one which they only can imagine, to the astronomical horizon of every place on the Earth, to the lunar horizon and so on.

Also, the view of the Earth and its representation in our mind can evolve to include the model of the globe. But people who accept that the Earth is round and is a sphere, with inhabitants all around and have a correct perception of gravity, say in Italian: from Rome "salgo a Milano" (I climb to Milano) or "scendo in Sicilia" (I go down to Sicily). The same in France: from Marseille they say "Je monte à Paris" (I go up to Paris). In Latin languages the everyday speech confuses going up, going to the bottom, going down with the directions of North-South on a sphere, like if... the Earth is plane like a map, a map on the wall of the classroom in a vertical position.

To help develop an idea of the Earth and their model we organize the International Globolocal Project that promotes the instrument I named "parallel globe" (See: www.globolocal.net ). The «commercial» globe we buy, is the same in Alaska and in Argentina! In this globe the north hemisphere is always on the top and a lot of adults have forgotten why the axis is inclined and what it represents. So, we suggest instead to put the globe, free from the axis, in a homothetic position with the Earth in space: every point on Earth will be on the top, and the North-South axis pointing to North and South. In this way the model begins as an instrument and when placed in sun light it is possible to see on the globe where day or night is, and where Winter or Summer is. Therefore, it respects the relativity of the point of view with the observer's symbolic, geographical and cultural aspects. It is a challenge for the people of the North, the West and the rich and technological countries because they could be in an upside down position, if the globe is in Kenya or Argentina. The use of the parallel globe puts in evidence that there is an implied, hidden, potentially dangerous power in a map!

\subsubsection{Analysis about the evolution of the conceptions}

In primary school we have recorded changing the way to describe the shadow phenomenon at Sun. The evolution of the concept is expressed in these sentences in successive periods:

- $\quad$ " In the early morning the Sun is low and the shadows are long, at noon the Sun is high and the shadows are short" (Descriptive expression)

- $\quad$ "In the morning the shadows are long because the Sun is low" "(Causal expressions)

- " If the Sun is low, the shadows are long" (Conditional expressions) (Di Ianni, 2012)

For every group of university students, I teach, I record the evolution of their concepts and knowledge about the observed Moon, which is a nonlinear evolution (Figure 10). This means that one group discovers before or after another group some aspects and it is difficult to predict exactly this path because it depends on what we can observe during the semester, if the sky is clear, etc. The group works through the observations of the sky, makes 
models using their bodies, discuss, draw, make new observations, and observations of models (Figure 11) during 2 to 3 months.

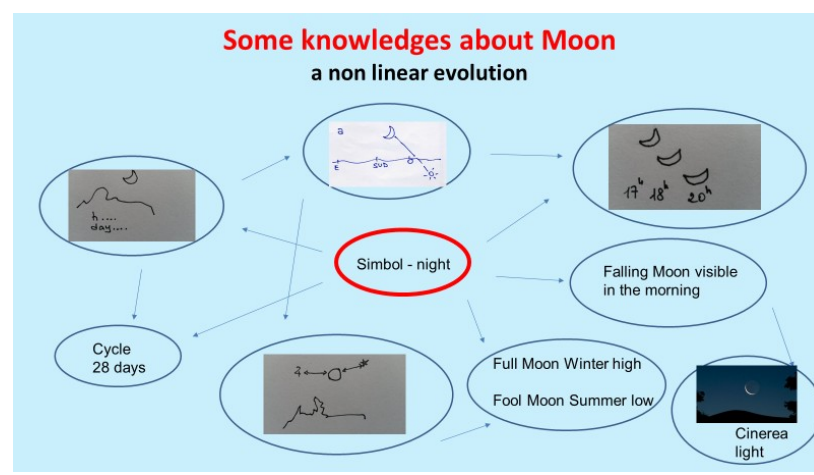

Figure 10

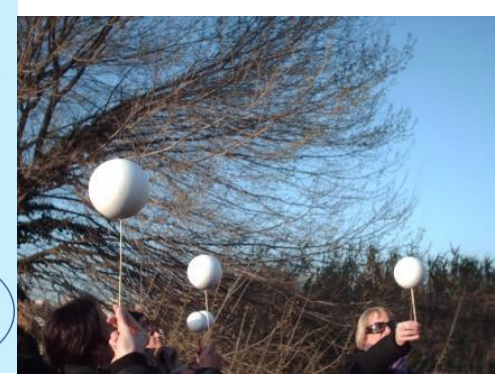

Figure 11

Very young children show symbolic abilities in recognizing the representations and the pictures of the Moon. Furthermore, children at the beginning ask "How many moons are there?" and "Do people in every country see the same Moon today?" Teachers must help learners to continue to pose questions and look for causal relationships. Going quickly through an activity with little time to study is a didactical model that in my research I define as dangerous: too little time to think or working in a hurry are problematical aspects of western schooling. Instead, writes Maffei, an Italian neurologist "Apparently the network communication speed also affects the brain by moving it to rapid thinking, but it is the slow thinking that is the basis for reflection and responsible decision making."

\section{Conclusions}

\subsection{Teacher's training and researchers in education}

In teaching, the methods are often very similar to those of scientific divulgation which present many arguments very quickly, without giving time to reflect and to ask questions. For example, the strong use of "virtual" reality atrophies the body and its perception.

Along which languages, which sectors, are we ready to adopt inter, multi and transdisciplinary approaches? I think that we have to be very open to rich experiences, having different meetings with artists, artisans, decision makers, and scientists, to be able to help students to develop and understand, themselves and take responsibility before the world, in communication and in social involvement. In my research I found that examples and not words are very important in people's formation and that they are more stable in memory and become the example to imitate. I think we need a lot of imagination to deal with issues that make sense.

Our horizon is the basis for recording the position of the stars, like I wrote before, also for collecting and recording our memories and our tales related to places (Figure 12) and also for "singing shapes", such as a musical score. We accept and we promote explicitly our bi-logic, in the sense of Matte Blanco, to develop topics of a scientific nature as well. 


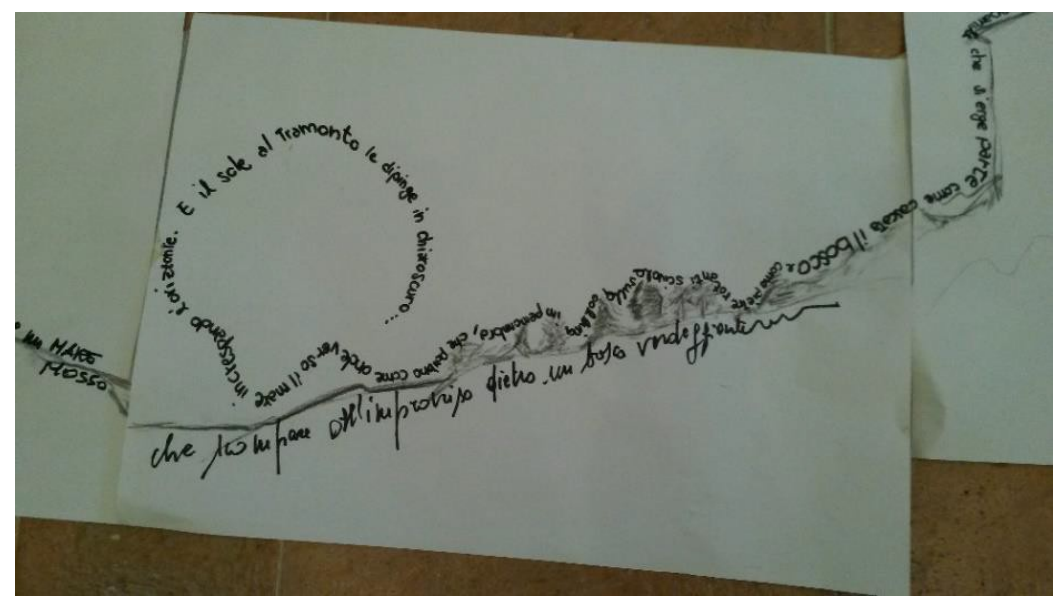

Figure 3

Many researchers say that it is very important to develop visuo-spatial thinking, to reach this goal we can attempt different ways and languages. In a residential course we started with a Caravaggio painting, projected onto a room wall. People are invited to paint the projected image on the wall and to pay special attention to the light, shadows and colors. After painting in $2 \mathrm{D}$, people are invited to choose characters in the painting and to place themselves in those positions, to look for the clothes of the same colors, and arrange the lights to obtain the same effects. In this way we realized a $3 \mathrm{D}$ transposition of the painting.

\subsection{Openings}

The Buddhist Monk Thich Nathan (1926-Vietnam) speaks about inter-connectedness and inter-dependence of people, of people and nature, of everything that exists and is made. This idea removes the borders and helps to see behind a sheet of paper the tree, the Sun, the rain on the tree, and the person who has cut the tree. Karen Michelle Barad (1956), an American feminist theorist, introduced a neologism, Intra-action, and signals an important challenge to individualist metaphysics. For Barad, phenomena or objects do not precede their interaction, rather, objects emerge through particular intra-actions.

\section{References}

1. Comenius, Didactica Magna, (Italian translation La Nuova Italia Ed, Firenze, 1952)

2. I. Matte Blanco, The Unconscious as Infinite Sets (Karmac, London,1975)

3. N. Lanciano, "L'horizon: un outil pour l'initiation à l'astronomie", Memoire de recherche Faculté de Psychologie et des Sciences de l'Education, Università di Ginevra 1988, stampato in proprio nel luglio 1996

4. N. Lanciano," "Ver y hablar como Tolomeo y pensar como Copérnico" Enseñanza de las ciencias", 7.2 http://www.raco.cat/index.php/Ensenanza/article/view/51253 (1989)

5. N. Lanciano, "L'analisi delle concezioni e l'osservazione in classe: strumenti per la definizione degli obiettivi educativi e delle strategie pedagogiche per l'insegnamento dell'Astronomia nella scuola elementare in Italia", Tesi di Dottorato n 235 in Sciences 
de l'Education, alla Faculté de Psychologie et des Sciences de l'Education, Università di Ginevra nel 1996, stampata in proprio nel 1997

6. Nicolescu B., 2006. Transdisciplinarity, past, present and future.

http://basarab- nicolescu.fr/Docs_articles/TRANSDISCIPLINARITY-PAST-

PRESENT-A ND-FUTURE.pdf

7. N. Lanciano, N. Camino, "Del angulo de la geometrìa a los àngulos en el cielo. Obstàculos para la conceptualizaciòn de las coordenadas astronòmicas", Enseñanza de las Ciencias, (Spagna) 26.1, p 77-92 (2008)

8. E. Giordano, N. Lanciano, O. Pantano, S. Rossi, Dalla terra all'universo: linee di un percorso dalla scuola dell'infanzia al termine della scuola secondaria superiore, by $\mathrm{P}$. Guidoni, O. Levrini, Approcci e proposte per l'insegnamento-apprendimento della fisica a livello pre-universitario dal Progetto PRIN-F21, (Forum, Udine, p 57-66, 2008)

9. S. Dehaene, La boss des maths, (Éditions Odile Jacob, Paris, 2010 )

10. E. Lazlo, Intervista a Ervin Laszlo - Integral Leadership Review - Gennaio 2013

11. R. Di Ianni, "Lavorare sulla competenza matematica con $i$ bambini della scuola primaria:

12.l'educazione alla congettura, al confronto, all'argomentazione attraverso un percorso di osservazio ne del cielo", (Tesi in Matematica, University of Pisa, A.A. 2012-13)

13. E. Giordano, M. Gagliardi, Metodi e strumenti per l'insegnamento e l'apprendimento della fisica, (EdiSES, Napoli, 2014)

14. L. Maffei, Elogio della ribellione, (Il Mulino, Bologna, 2016)

15. N. Lanciano, Strumenti per i giardini del cielo, (Spaggiari-Junior, Parma, 2016)

16. N. Lanciano, M. Berardo, Eratóstenes: um exemplo de trabalho com estudiantes universitários em didática e história da astronomia. (RELEA 2, p 7-19, 2016) http://www.relea.ufscar.br/index.php/relea/article/view/276/329 